\title{
Redescubrimiento del sitio arqueológico de la momia que inspiró a Gauguin y Munch
}

Recibido: 21.06 .18

Aprobado: 21.09 .18

\author{
Stefan Ziemendorff \\ Universidad de Rostock, Alemania \\ sziemendorff@gmail.com
}

\begin{abstract}
RESUMEN
En artículos anteriores se mostró la gran influencia de una momia chachapoya en el arte moderno, específicamente sobre las obras de Paul Gauguin y de Edvard Munch, así por ejemplo en su famoso cuadro El Grito y, inspiradas en éstos, de forma directa o indirecta, en muchísimas obras de arte a nivel mundial desde hace ya más de un siglo. Por la importancia de la momia en esta parte de la historia del arte, es de sumo interés recopilar datos acerca de su procedencia e historia, en específico sobre el lugar y las circunstancias bajo las cuales fue hallada y llegó a París. Además, la momia es identificada como la de un guerrero de la cultura chachapoya.
\end{abstract}

Palabras Clave: chachapoya; momia; historia de arte; Edvard Munch; Paul Gauguin.

\section{The rediscovery of an archaeological mummy site that inspired Gauchin and Munch}

\begin{abstract}
It has been previously shown that a Peruvian Chachapoyan mummy has exerted an enormous influence upon the world of modern art, specifically the works of Paul Gauguin and Edvard Munch. Not only is Munch's famous «The Scream» inspired by this ancient artifact; the mummy has has been directly and indirectly inspiring artists around the world for more than a century. Because of its role in modern art history, it is vitally important to understand and collect all the facts related to the origin and history of the mummy, especially how it was found and how it came to Paris in the late nineteenth century. Additionally the mummy is now known as the remains of a Chachapoyan warrior.
\end{abstract}

KeYwords: Chachapoya; mummy; Art history; Edvard Munch; Paul Gauguin. 


\section{Introducción}

n otro lugar se ha podido ha podido demostrar la importancia de una momia chachapoya para el arte de Paul Gauguin, quien llegó a crear una veintena de obras inspiradas en ella, entre ellos la «Eva bretona» (Fig. 1). Gauguin usó la momia como instrumento para implementar su plan artístico de revolucionar el arte occidental con la imaginería y de culturas considerados por él primitivas (Ziemendorff, 2014).

Debido a la influencia que el plan artístico de Gauguin generó a fines del siglo xix y comienzos del $\mathrm{xx}$, otros artistas no solo usaron grandes partes de sus conceptos artísticos, sino también parte de su imaginería, entre ellos la momia chachapoya (Ziemendorff, 2016). La obra más conocida de estas es el mundialmente famoso «El Grito» del pintor noruego Edvard Munch (Fig. 2), quién convierte al imagen de la momia chachapoya en el icono mundial de angustia y terror (Ziemendorff, 2015).

Tanto desde la

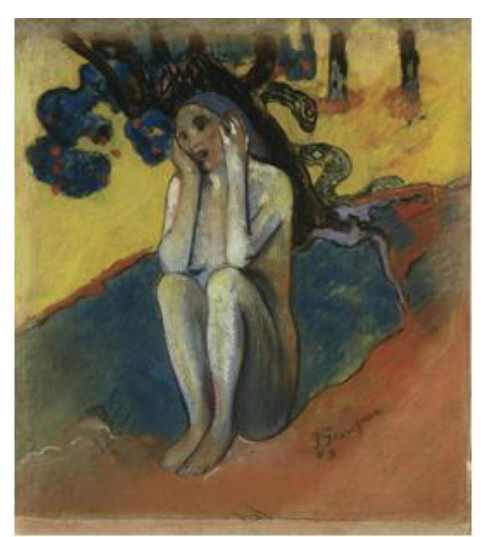

Figura 1: Eve bretonne (francés: Eva bretona, Paul Gauguin)

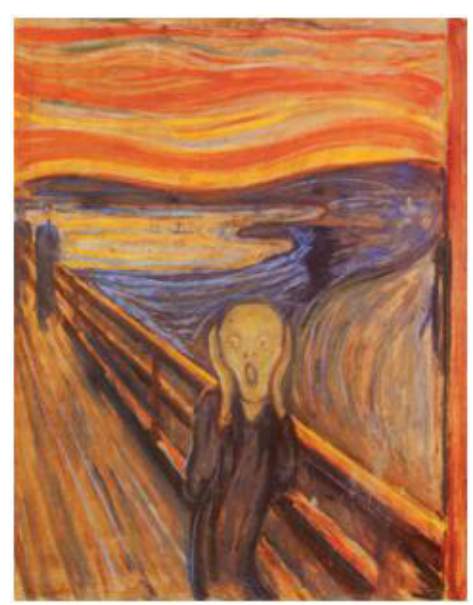

Figura 2: «El Grito» de 1893 (E. Munch) perspectiva de la historia del arte como desde una perspectiva práctica, la de promoción turística por ejemplo es de sumo interés averiguar más sobre esta momia. Es por ello que en este lugar se responderá a las preguntas acerca de su procedencia, la forma de que llegó desde la región de Chachapoyas a París, las circunstancias en las cuales fue encontrada y qué aspectos de interés se pueden rescatar sobre el individuo momificado y los objetos hallados junto con la momia; y finalmente de cual sitio exactamente fue rescatado.

La momia pertenece a la cultura Chachapoya o Chachapoyas, la que se desarrolló en un ámbito de la ceja de selva en partes de los actuales departamentos peruanos de Amazonas, San Martín y La Libertad. Consistía en varios subgrupos étnicos que mantenían ciertos rasgos comunes pero que estaban políticamente independientes. Alrededor del año 1470 fueron conquistadas por el Inca Tupac Yupanqui e incorporadas al Tahuantinsuyo.

\section{La procedencia de la momia}

La imagen de la momia a la cual se atribuye haber sido una importante fuente de inspiración para Paul Gauguin, Edvard Munch y muchos otros artistas ha sido reproducida frecuentemente en las publicaciones sobre los pintores mencionados; entre ellas hay que destacar tanto los textos que por primera vez constatan la influencia de la momia en el arte de Gauguin y Munch (Andersen, 1967, pp. 238-242; Rosenblum, 1978, pp. 7-8) como sus biografías más conocidas (Sweetman, 1995, p. 85; Bischoff, 2005, p. 53). Luego la momia también aparece en varios documentales sobre Gauguin y Munch, mientras que, mediante la reproducción de su foto junto con un bosquejo de la momia efectuado por Paul Gauguin, Richard S. Field demuestra que la previa identificación de la momia por los historiadores de arte mencionados es correcta (Field et al., 1973, p. 50).

Ya en el año 1967 Wayne V. Andersen indica de qué momia precisa se trata, escribiendo que en 1878 el Museo etnográfico del Trocadéro adquirió la momia y haciendo referencia al catálogo de la galería americana del museo de 1897 (Hamy, 1897, pp. 65-66). En dicho catálogo se especifica que la momia proviene del sitio Piedra Grande del Utcubamba, un lugar arqueológico cerca de la ciudad de Chachapoyas en el norte del Perú, indicando que fue extraída de ahí por el francés Pierre Vidal-Senèze en 1877. También se reproducen dos fotografías de la momia (Fig. 3), siendo la fotografía derecha la misma que figura en las fuentes citadas 


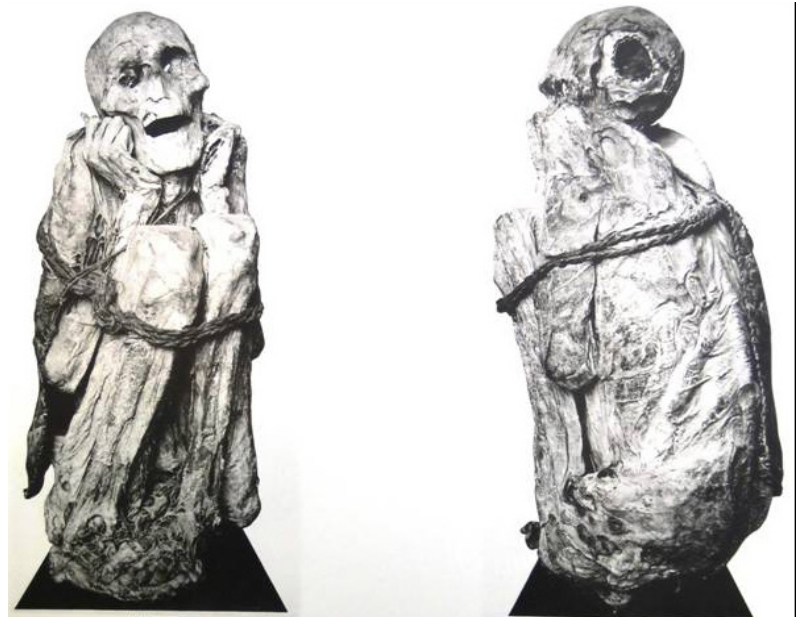

Figura 3: Fotos de la momia (Hamy, 1897: Lamina XXXIII)

arriba. Se distingue por tener una trepanación craneal y estar provista de una bolsa.

La proveniencia de la momia se confirma en el catálogo electrónico actual del otrora Museo etnográfico del Trocadéro, ahora Museo del Hombre (Musée du quai Branly, 2006), donde la momia figura con el numero de inventario 71.1879.1.22.1, perteneciente a un grupo de 22 objetos cuyo lugar de procedencia es igualmente Piedra Grande (Chachapoyas), todos donados por Pierre Vidal-Senèze (precisamente dice: «M.H. Département d'Amérique (coll. Vidal-Senèze). Lieu: Env. de Chapapapoyas, Piedra Grande»). Es importante señalar que una foto de varios bosquejos de la momia que realizó Paul Gauguin en 1887/88 forma parte del expediente de la colección Vidal-Senèze, figurando con el código: D002547/40848. Un artículo del descubridor de la momia, Pierre Vidal-Senèze, de 1877, es decir del mismo año del descubrimiento de la momia, afirma que él encontró esta momia, mencionando específicamente tanto la trepanación como la bolsa colgada en la momia (Vidal-Senèze et al., 1877, pp. 640641.). Además menciona que la sacó de un sarcófago antropomorfo.

El acto de venta de la momia en París por VidalSenèze en 1878 (junto con los otros objetos mencionados arriba) se documenta en el capítulo concerniente al viajero francés en el libro «Los viajeros franceses en busca del Perú antiguo 1821-1914» (Riviale, 2000, pp. 180).

Por todo lo indicado, no cabe duda alguna de que la momia a la cual se atribuye haber inspirado a los pintores Paul Gauguin y Edvard Munch proviene de un sitio arqueológico del valle de Utcubamba cerca de Chachapoyas, de donde fue extraída en 1877 por Pierre Vidal-Senèze.

Lo poco que se sabe sobre el descubridor de la momia, Pierre Vidal-Senèze, ya ha sido recopilado en el libro arriba citado (Riviale, 2000, pp. 174-181), en el cual se afirma que fue un hombre de poca instrucción, quien después de terminar su aprendizaje como horticultor participó como voluntario en la guerra franco-alemana 1870/71 y luego emprendió un viaje a América con su antiguo comandante, con la finalidad de acumular colecciones botánicas para su posterior venta en Europa. En el transcurso de su viaje por Canadá, EE.UU., México, Brasil y el Caribe, se enteró de que los restos arqueológicos también eran un bien coleccionable de igual o más valor que las plantas exóticas, por lo cual también empezó a interesarse por ellos.

En 1876 viaja en compañía de un naturalista, el suizo Jean Noetzli, desde Guayaquil por Loja y Bagua hasta la ciudad de Chachapoyas, adonde llega en 1877 , tomando noticia de ruinas muy particulares. Se decide a visitarlas, entre otras las del sitio Piedra Grande del Utcubamba (sin su compañero suizo); es ahí que extrae de un sarcófago antropomorfo la momia que nos interesa en el contexto del presente artículo. Hay que resaltar que extrajo un total de cuatro momias, pero por dificultades de transporte solo llevó una - la momia trepanada en cuestión - a París, mientras las otras tres dejó «en una cueva a unos días de marcha de Bella Vista» (Riviale, 2000, p. 175), refiriéndose al Bellavista ubicado cercano a las orillas del Marañón entre Bagua y Jaén.

En París la momia causó cierto interés científico, por lo cual la que el trajo fue adquirido junto con los demás objetos traídos del mismo sitio, para que todo sea incluido a la colección americana expuesta en el Museo etnográfico del Trocadéro. Así mismo, VidalSenèze fue comisionado a volver inmediatamente a Chachapoyas para que traiga los otros objetos que había dejado ahí, entre ellos las tres momias faltantes, y reúna más artefactos. Sin embargo no llegó a cumplir esta misión, ya que poco después de su llegada a Guayaquil expiró el 5 de octubre de 1878, así que la momia de Piedra Grande del Utcubamba ya expuesta en el Museo del Trocadéro siguió siendo la única que llegó a París. (Riviale, 2000, pp. 174-181). 


\section{La momia de un guerrero chachapoya en un sarcófago antropomorfo}

Los sarcófagos descritos por Vidal-Senèze corresponden al padrón funerario de un subgrupo étnico de la cultura chachapoya, el cual se limita a un área dentro de la actual provincia de Luya; los sarcófagos típicos de este grupo chachapoya fueron construidos desde la segunda mitad del segundo milenio de nuestro tiempo hasta entrando en la época colonial temprana (grupo ejemplar en Fig. 4).

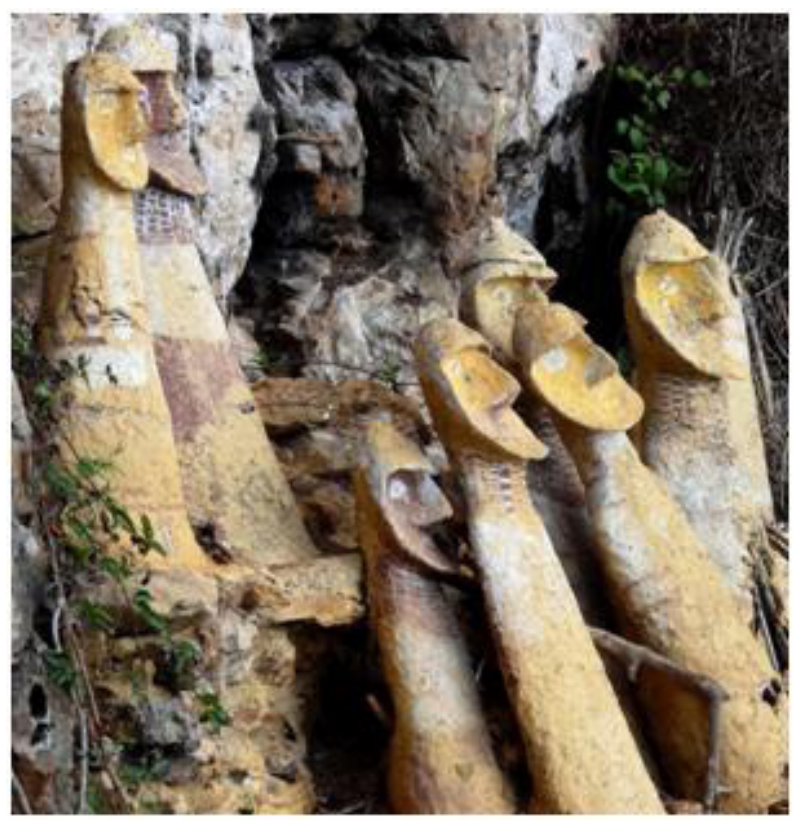

Figura 4: Sarcófagos antropomorfos (Foto: Autor)

Las describe de la forma siguiente "Las tumbas son coniformes, como colmenas de abejas, con unos dos metros de circunferencia y una altura de 1,25 a 1,5 metros. Son construidos de una mescla de barro, conteniendo materiales de origen animal y vegetal, así como piedras.» (Vidal-Senèze et al., 1877: 640, traducción propia).

Si bien no se dispone de mucha información sobre la momia misma, los datos conocidos permiten, en su conjunto, afirmar que la momia llevada a París es la de un guerrero:

1. El sarcófago antropomorfo del cual proviene la momia ostentaba cabezas trofeo estilizadas pintadas de rojo, típicas para sarcófagos chachapoya que contenían los restos mortales de guerreros.

2. Se trata de un joven individuo masculino.
3. El cráneo de la momia había sido trepanada, operación que se aplicaba mayormente a guerreros heridos en combate.

Detallando las pruebas: Pierre Vidal-Senèze describe que sacó las momias de sarcófagos muy particulares que tenían cabezas antropomorfas y, encima de estas cabezas de adobe, otras cabezas (Vidal-Senèze et al., 1877: 640-641). Existen varios sarcófagos conocidos de este tipo en la provincia de Luya (Fig. 5). Según los estudios recientes del arqueólogo alemán Dr. Klaus Koschmieder, las pequeñas cabezas encima de la cabeza del sarcófago representan cabezas trofeo y los sarcófagos, por ende, son tumbas de guerreros (Koschmieder, 2012: 58).
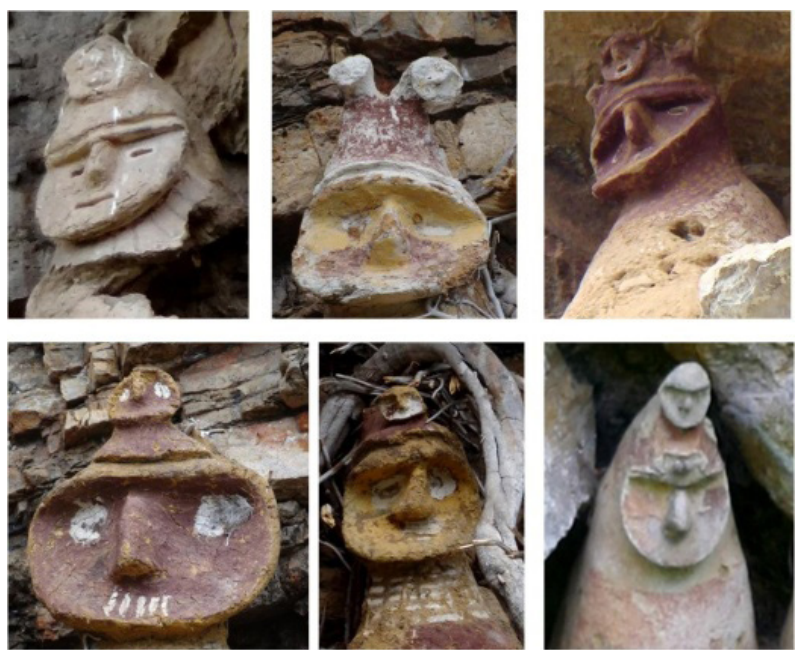

Figura 5: Cabezas de sarcófagos con cabezas trofeo (Fotos: Autor)

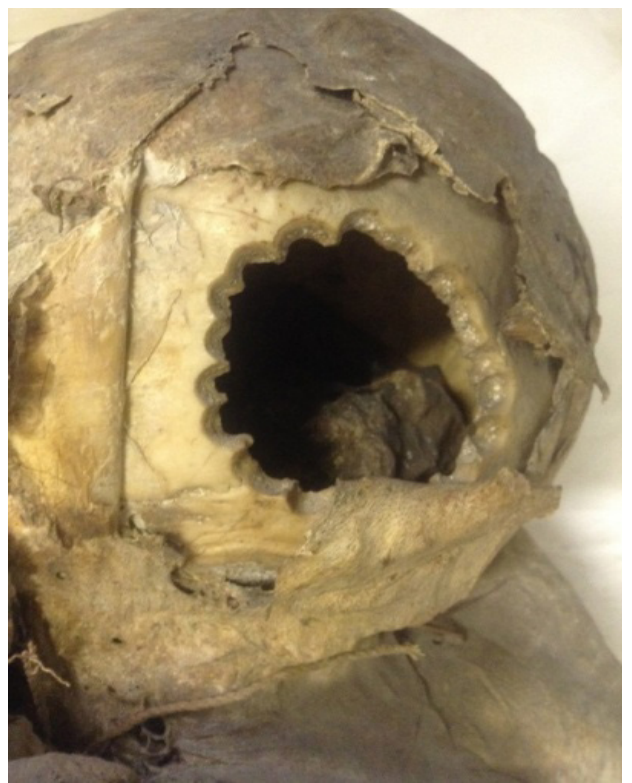

Figura 6:

Trepanación craneal de la momia (Cortesía Clement Laronde) 
Un equipo francés que examinó la momia (el arqueólogo Dr. Arnaud Ansart y los radiólogos Samuel Mérigeaud del Hospital Universitario de Montpellier e Isabelle Huynh-Charlier del Hospital La Pitié Salpétrière de París) aportó importante información adicional que ha permitido su identificación como un guerrero, ya que se trata de un joven adulto masculino (com. pers).

La confirmación final de la identidad de la momia es su trepanación en la cabeza (Fig. 6), una operación típica de su época que se realizaba cuando los guerreros habían recibido impactos en la cabeza por la porra, el arma más usada en los tiempos prehispánicos en toda la zona andina, o por piedras arrojadas mediante la honda. La operación sirvió para retirar restos del hueso o de las armas que apretaban el cerebro o para drenar hemorragias y de esta manera aliviar el fuerte dolor. La técnica de trepanación es llamada "corona de ebanista» y consiste en la perforación de pequeños huecos alrededor de la herida con la finalidad de poder sacar la parte central del hueso.

Cabe indicar que, por supuesto, no todas las lesiones en la cabeza que se trató de curar con trepanaciones fueron necesariamente causadas por acciones violentas, sino podían también provenir de caídas en la cabeza u otros accidentes. Sin embargo, en el caso de la momia aquí tratada, es evidente que la herida por curar fue causada por actos de guerra, ya que Vidal-Senèze menciona que, en las ruinas de Piedra Grande, "casi todas las momias tienen un círculo de huecos pequeños en la frente o en la región occipital de la cabeza» (Vidal-Senèze et al., 1877, p. 641, traducción propia). Ello se ve confirmado por una calavera del mismo sitio, igualmente con una trepanación, que el francés lleva a París junto con la momia.

Las lesiones en la cabeza y/o trepanaciones son de una frecuencia inusual en la zona de la cultura chachapoya (Koschmieder et al., 2010, p. 20), sin duda debido a las hostilidades entre las diferentes etnias chachapoya y los continuos conflictos con los incas, los cuales conquistaron la zona alrededor de 1475 . Según el médico francés Just Lucas-Championniére (Lucas-Championnière, 1912, p. 61) y también acorde a la opinión de los expertos peruanos en medicina prehispánica Juan B. Lastres y Fernando Cabieses (Lastres et al., 1960, p. 152), la trepanación de la momia en cuestión no presenta signos de supervivencia del individuo, es decir una reacción biológica en el cráneo trepanado, mientras un equipo francés que estudió la momia y su trepanación a profundidad inicialmente se inclinó por la una posición parecida, es decir que la trepanación era peri o post mortem (Bou et al., 2016). Dicho equipo logró realizar pruebas experimentales con puntas de silex en réplicas de cráneos, comparando el resultado con otras trepanaciones, concluyendo que es un poco más probable que se trate de una trepanación ante mortem o perimortem - quiere decir que el guerrero sobrevivió la trepanación, pero por muy poco tiempo (com. pers con Bou, 2017).

\section{Otros datos sobre la momia}

Pierre Vidal-Senèze indica que, de las cuatro momias que había encontrado, tuvo que dejar atrás tres, envueltas en textiles, tal como las había encontrado en sus sarcófagos, mientras que desenvolvió la cuarta entonces la que llevó a París -, como aún lo demuestran las marcas de textil en su piel, y encontró una bolsa con diseños geométricos colgada en su cuello (Vidal-Senèze et al., 1877, p. 641). En el ya mencionado inventario del Museo del Hombre esta bolsa es identificada como una chuspa o bolsa de coca (Musée du quai Branly, 2006). Si bien no se dispone de conocimientos acerca del contenido de esta bolsa, es probable que haya contenido hojas de coca, es decir la ofrenda típica a los muertos en toda el área andina. Durante más de 100 ańos la momia chachapoya se expuso junto con esta bolsa (Fig. 7).

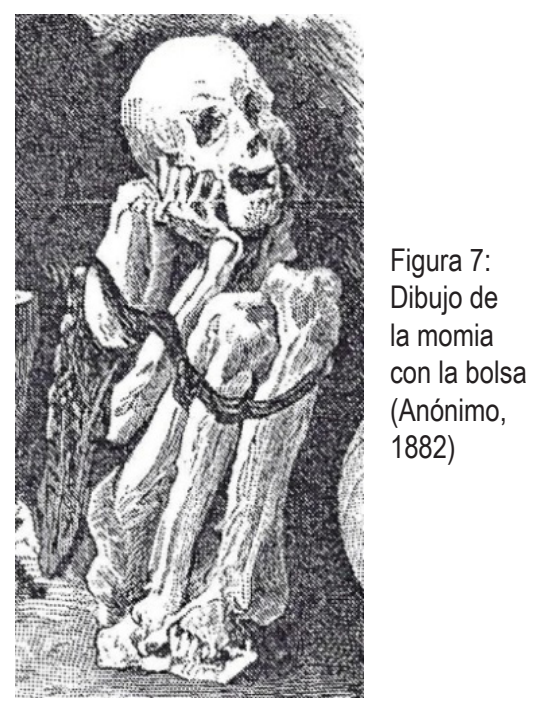


A parte de la bolsa, hay una serie de objetos hallados por Vidal-Senèze, todos provenientes de Piedra Grande del Utcubamba, pero no se conoce con precisión su antigua disposición dentro o alrededor de los sarcófagos. Entre los objetos destaca una serie de tres caleros, implementos indispensables para el chacchado de la coca. Su hallazgo parece confirmar la identificación de la bolsa como una chuspa.

Adicionalmente Vidal-Senèze encontró dos hachas de piedra, algunos instrumentos de hueso, una sonaja de bronce y varias cerámicas, algunas de ellas con diseños zoomorfos. Su estilo fue identificado como chachapoya-colonial por el arqueólogo francés Olivier Fabre (Fabre, 2000: 64).

No figura en la colección del Museo del Hombre, pero sí en el acta de venta de los objetos de 1878un «manojo de plantas halladas en las manos de una momia» (Riviale, 2000: 180). No está claro si Pierre Vidal-Senèze lo halló en las manos de la momia aquí tratada o en las manos de las tres momias que dejó, aunque lo primero es bastante probable, porque ésta fue la única momia que desenvolvió. Otro dato interesante se obtuvo en una conversación con la actual curadora de las momias del Museo del Hombre, Anne Raggi, que indica que la momia preserva sus intestinos. Al igual que Vidal-Senèze observa también la inusual blancura de la piel de la momia que posiblemente se debe al proceso de momificación, del cual sin embargo aún no se dispone de mayores datos.

\section{Redescubrimiento de Piedra Grande del Utcubamba}

De los documentos que deja Vidal-Senèze se desprende que el sitio arqueológico del cual extrajo la momia se llamaba —en su tiempo-Piedra Grande, llamándolo Piedra Grande del Utcubamba para distinguirlo de otro Piedra Grande ubicado cerca del pueblo de Colcamar, a varias horas del río Utcubamba. El lugar en cuestión queda cerca del Puente Utcubamba, un caserío que hasta el día de hoy mantiene este mismo nombre debido al puente que cruza el río Utcubamba ahí (Fig. 8). Hace años un puente de concreto fue construido en este sitio, sin embargo los cimientos del antiguo puente son aún visibles a pocos metros de distancia. Ahí es donde el explorador dejó su

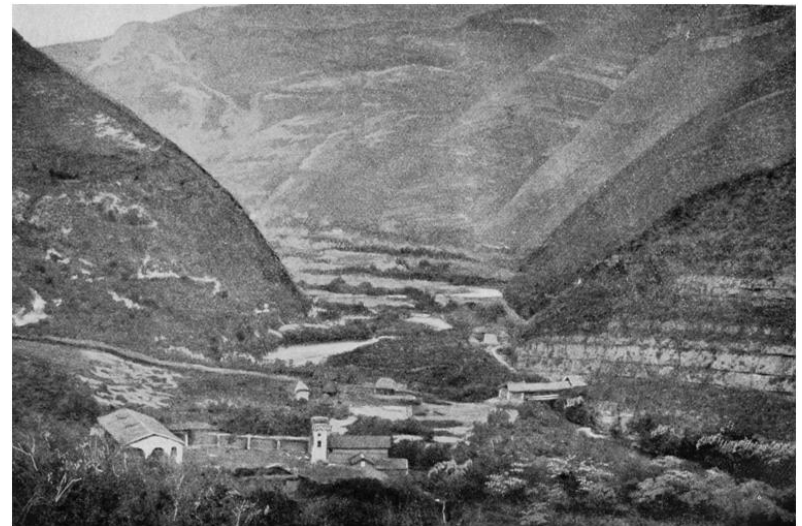

Figura 8: El poblado «Puente Utcubamba» con el puento sobre el rio Utcubamba. Foto tomada en 1887 a 10 años luego que Vidal-Senèze la cruzó para extraer a la momia (Middendorf 1895: 258)

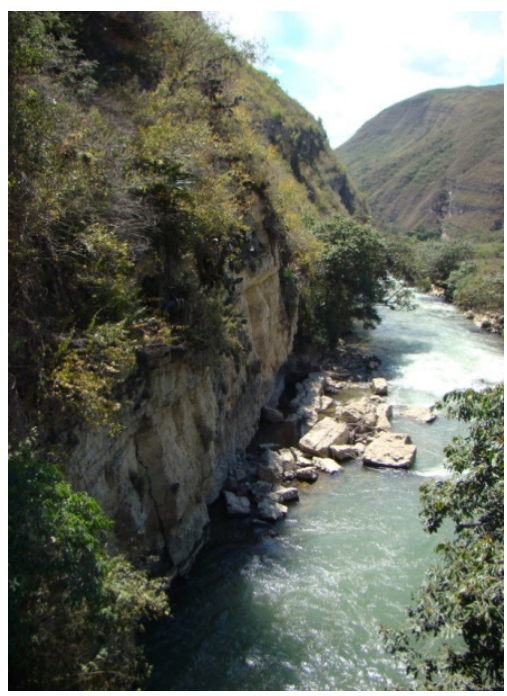

Figura 9: Foto desde Puente Utcubamba hacia el norte (Foto: Autor)

mula y cruzó el río. Más precisamente Pierre VidalSenèze dice que para regresar del sitio arqueológico a Chachapoyas tuvo que cruzar el puente. Desde el puente continuó por la orilla del río, lo que es solamente posible hacia el sur, ya que hacia el norte —río abajo- no es posible caminar por la orilla, porque no la hay, sólo un barranco que se extiende por una distancia de cientos de metros (Fig. 9). Luego, desde la orilla Vidal-Senèze avistó varias estructuras arqueológicas: «Debajo de la cima del cerro percibí una cantidad de conos, de los cuales algunos estaban provistos de máscaras antropomorfas. Viéndolos desde abajo, no se los podía ver muy bien para dibujarlos, y la subida me parecía tan difícil como peligrosa». Aún así, al día siguiente se subió al cerro para llegar a un grupo de sarcófagos, de donde extrae la momia (Vidal-Senèze, 1885, p. 589, traducción propia). 


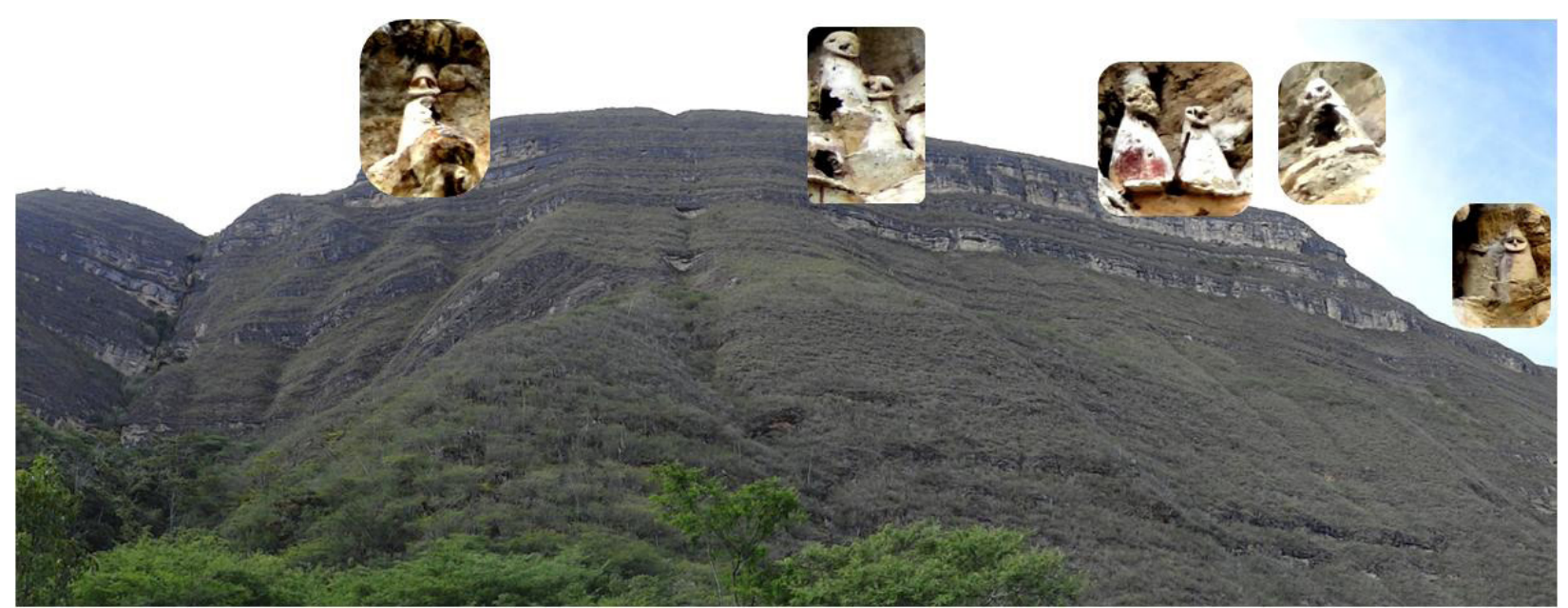

Figura 10: Foto del Cerro Ángulo desde la orilla del río Utcubamba (Foto: Autor)

El autor del presente artículo siguió la ruta descrita por Vidal-Senèze, es decir cruzó el puente del caserío Puente Utcubamba y siguió la orilla del río hacia el sur, donde, después de una distancia de un poco más de medio kilómetro, aparece un cerro llamado hoy Cerro Ángulo por los pobladores del caserío mencionado. Se ubica en el distrito de Inguilpata, en la provincia de Luya del Departamento de Amazonas. En las faldas de este cerro, a lo largo de casi un kilometro, se nota una gran cantidad de estructuras arqueológicas, entre ellas muchos sarcófagos antropomorfos, pero - tal como lo describe Vidal-Senèze - se ubican a una distancia que dificulta ver detalles. Algunos de los sarcófagos se resaltan en la fig. 10, que muestra la vista al Cerro Ángulo desde el río Utcubamba a unos 700 metros al sur de Puente Utcubamba.

Igualmente en el Cerro Ángulo se observan restos de lo que Vidal-Senèze identificó como habitaciones, pero que probablemente serán restos de mausoleos, así como pinturas rupestres de color rojo, las cuales él llamó «jeroglíficos».

Un reconocimiento de la zona por la orilla, tanto hacia el norte como hacia el sur de Puente Utcubamba probó la inexistencia de otros sitios con características lejanamente parecidas, sólo registrando algunas estructuras en el fundo Achamaqui a unos tres kilómetros río abajo. En este punto existen varios restos arqueológicos, entre ellos un grupo de sarcófagos, ubicado a pocos metros sobre el río, que no coincide con la descripción de Vidal-Senèze ni es accesible desde su punto de partida. Otros restos que existen en el mismo fundo no se notan desde la orilla del río, son igualmente inaccesibles desde el Puente Utcubamba y luego resulta

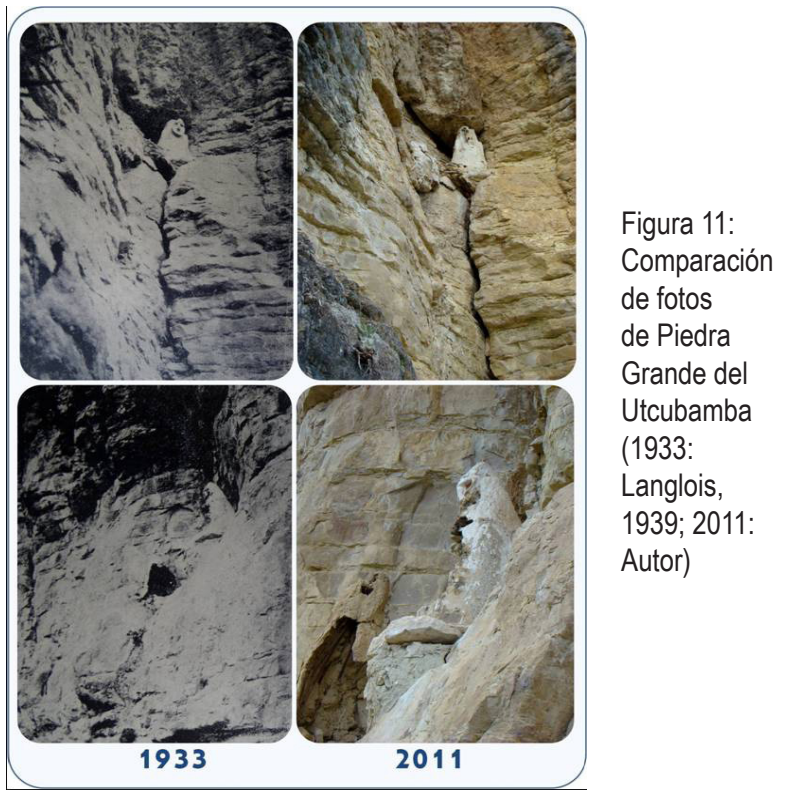

imposible llegar ahí desde el río sin equipo de escalar, además que carecen por lo menos al día de hoy de sarcófagos. Dicho con otras palabras: El Cerro Ángulo no es solamente el sitio al cual se llega de forma automática al seguir la descripción de la ruta de Vidal-Senèze e idéntico a la caracterización que da el francés, sino tampoco existe alternativa alguna que pudiera permitir formular una hipótesis alternativa.

El sitio indicado por Pierre Vidal-Senèze fue nuevamente visitado en 1933, por el investigador francés Louis Langlois (Langlois, 1939: 70 y 77), quien tomó fotografías del lugar que igualmente denominaba Piedra Grande del Utcubamba. Sus imágenes permiten constatar que se trata efectivamente del sitio llamado hoy Cerro Ángulo (Fig. 11). 
También destruye algunos sarcófagos, pero al contrario de Vidal-Senèze lo hace con la finalidad de obtener algunas cabezas de sarcófagos, las cuales consigue mediante varios tiros de escopeta a los restos arqueológicos. El siguiente investigador por llegar al sitio es Bertrand Flornoy, en 1941/42, nuevamente de nacionalidad francesa, quien denomina el sitio ya Ángulo. Él logra llevarse un sarcófago casi entero, el cual separa de su base usando un martillo y un cincel (Flornoy, 1945: 243).

Asimismo, la ubicación del sitio se ve confirmada por la descripción que dan los esposos franceses Henri y Paule Reichlen de su expedición al valle del Utcubamba, ubicando el Cerro Ángulo en lo alto de una pared de roca sobre las ruinas de Puente Utcubamba y mencionan que el sitio fue descubierto por Vidal-Senèze (Reichlen et al., 1950: 233), aunque en un mapa dibujado a mano invierten la ubicación de Puente Utcubamba y la de Piedra Grande. Sin embargo no queda duda de que se refieren al mismo sitio que se ha identificado en el presente artículo, ya que existen algunas fotos que tomaron del Cerro Ángulo, y no hay otro sitio arqueológico consignado en su mapa.

\section{Identificación del grupo de sarcófagos en Piedra Grande del Utcubamba}

Una vez ubicado el sitio arqueológico Piedra Grande del Utcubamba, el autor del presente artículo intentó ubicar el sitio preciso entre los diferentes grupos de sarcófagos del Cerro Ángulo, de los cuales al día de hoy quedan por lo menos unos 30, repartidos a grupos en lugares distintos y apartados entre sí. El Cerro Ángulo tiene una extensión de casi un kilómetro y está salpicado con sarcófagos aislados y con grupos de sarcófagos. Para poder dar con el grupo preciso del cual proviene la momia, se han establecido los criterios siguientes, acorde a la descripción de VidalSenèze (Vidal-Senèze et al., 1877; Vidal-Senèze, 1885):

1. Se trata de un grupo de muchos sarcófagos (y no sarcófagos aislados).

2. El Grupo debe ser visible desde el río.

3. El acceso al grupo debe ser difícil, escalando en partes sin equipo, por una ruta directa desde la orilla del río, pero no imposible.
4. Contiene un mínimo de cuatro sarcófagos destruidos, ya que Vidal-Senèze destruyó cuatro.

5. Las destrucciones en los sarcófagos no son recientes.

Recorriendo el pie del cerro y partes de sus faldas, se constató que la ruta que tomó Louis Langlois en 1933 hasta los sarcófagos mostrados en sus fotos no presenta las características descritas por Vidal-Senèze, porque en esta ruta, contrastando con las descripciones de Pierre Vidal- Senèze, no es necesario agarrarse en las plantas para subir, ni es directa desde el río, sino hay que ladear el cerro primero. Además en este sitio solamente hay sarcófagos aislados, no se encuentran grupos como la que menciona Vidal- Senèze.

Pero existe otro grupo que cumple con todos los criterios:

1. Es un grupo de sarcófagos, no se trata de sarcófagos aislados.

2. Es el grupo mejor visible desde el río y de aparentemente más fácil acceso desde este mismo punto.

3. Es posible llegar al sitio desde el río; al contrario los grupos de más arriba son aparentemente inaccesible. Pero: Es muy difícil llegar al grupo en cuestión, es necesario agarrarse en plantas espinosas y subir gateando, tal como lo describe Vidal-Senèze.

4. Contiene cuatro o más sarcófagos con destrucciones claramente visibles (ver flechas rojas en Fig.12).

5. Se ha confirmado que la destrucción no es reciente. Para ello se entrevistó al agricultor Rómulo Severo Silva Vargas, de 69 años. Su casa se ubica justamente debajo del grupo de los sarcófagos mencionados, los cuales son perfectamente visibles desde ahí. Cuando Silva Vargas se instaló ahí en 1978, dichos sarcófagos ya estaban destruidos, es decir la destrucción no se debe a un saqueo reciente. Este hecho por sí solo no constituye una prueba, porque podrían haber sido destruidos entre 1877 y 1978, sin embargo es el mejor dato con que se cuenta, sin pruebas que demuestren lo contrario.

Hay un valioso argumento adicional que no ha sido contemplado en nuestros criterios iníciales, ya que Pierre Vidal- Senèze no lo incluye en su des- 


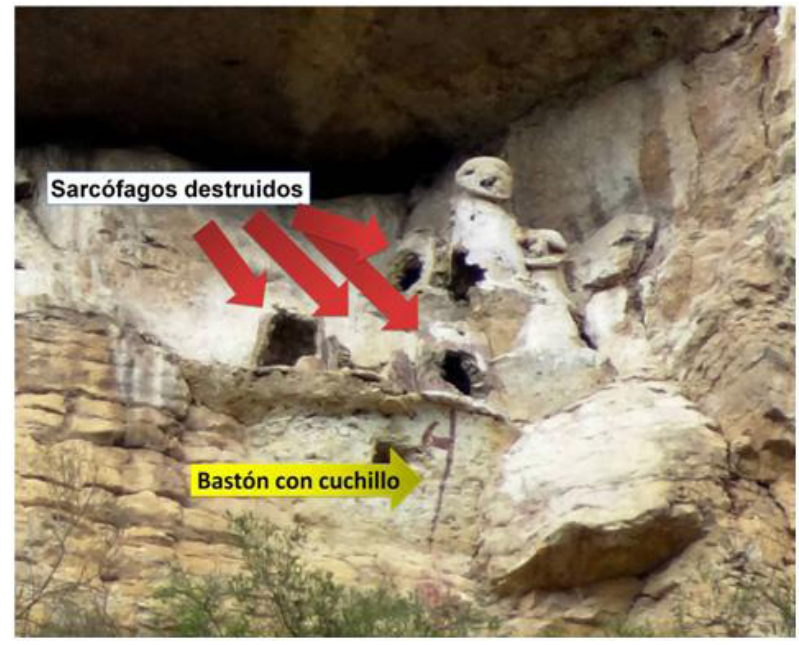

Figura 12: Probable sitio de proveniencia de la momia (Foto: Autor)

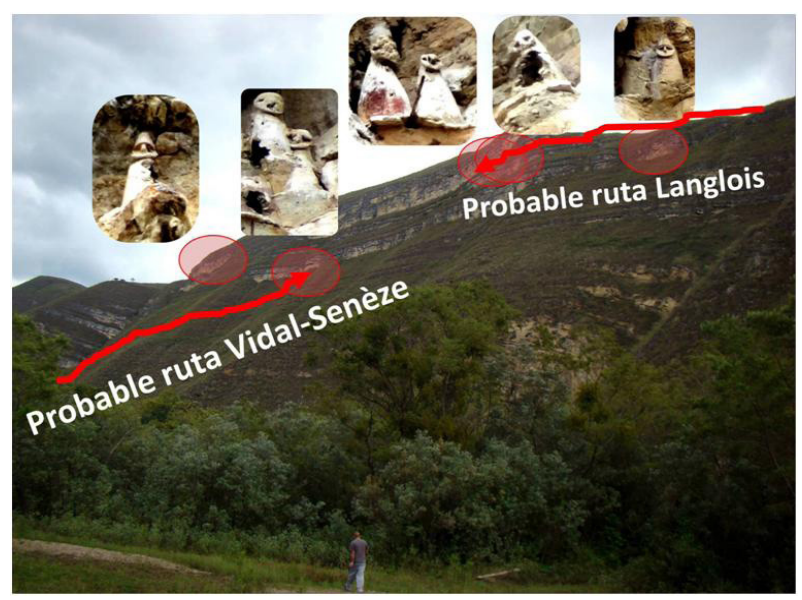

Figura 13: Probables rutas de exploración de Vidal-Senèze y Langlois (Foto: Autor)

cripción, sino se basa en las conclusiones acerca de la momia. El grupo identificado ostenta una pintura rupestre en forma de un bastón con cuchillo (ver flecha amarilla en la figura 12), lo que constituye una prueba perfecta de que en ese lugar se encuentra la tumba de uno o varios guerreros (Koschmieder et al., 2010: 29). Como se ha mostrado en un acápite anterior: La momia es la de un guerrero, y por ende la señal de bastón con cuchillo es un muy buen indicador adicional de que el grupo ha sido identificado correctamente.

Las rutas probablemente recorridas por VidalSenèze y Langlois (según las fotos presentadas en el acápite anterior) serán entonces las que se muestran en la figura 13. Mientras la de Langlois ladea el cerro por el antiguo camino a Inguilpata, la de Vidal-Senèze lleva al grupo de sarcófagos de donde proviene la momia que inspiró a Paul Gauguin, Edvard Munch y tantos otros artistas para la creación de decenas de obras de arte importantes.

\section{Conclusiones}

En el presente artículo se ha llegado a las conclusiones siguientes:

1. La momia inspiró a los pintores Paul Gauguin, Edvard Munch y muchos artistas más fue hallada en 1877 por el horticultor y botánico francés Pierre Vidal-Senèze, junto con otros objetos arqueológicos, y vendida por su descubridor en 1878 en París, donde posteriormente se expuso en el recién creado Museo etnográfico del Trocadéro.

2. La momia pertenece a un guerrero; esta identificación se basa en las evidencias siguientes:

a. Fue sacada de un sarcófago decorado con cabezas trofeos, las cuales correspondían a guerreros difuntos en la cultura chachapoya.

b. Se trata de la momia de un adulto masculino $y$ joven.

c. Presenta una trepanación craneal, aplicada frecuentemente a heridas del cráneo causadas por el impacto de una porra.

3. La momia que inspiró a los pintores Paul Gauguin, Edvard Munch y muchos artistas más proviene del sitio Piedra Grande del Utcubamba, ubicado cerca de la ciudad de Chachapoyas en el Departamento de Amazonas.

4. El sitio Piedra Grande del Utcubamba hoy es llamado Cerro Ángulo. Se ha podido identificar gracias a los indicios y evidencias siguientes:

a. Se ubica en el margen izquierdo del río Utcubamba, a poca distancia del caserío Puente Utcubamba, justamente en la dirección sur que es la única vía que se puede tomar por orillas del río desde Puente Utcubamba. Por eso la ruta coincide perfectamente en la descripción de la ruta que tomó Vidal-Senèze.

b. Los sarcófagos son visibles desde la orilla del río, pero tal como anota Vidal-Senèze, están a una distancia que no permite reconocer detalles. 
c. A parte de sarcófagos, en el mismo sitio existen muros de lo que Vidal-Senèze llama «habitaciones», que en realidad probablemente son restos de mausoleos.

d. Algunos de los sarcófagos son accesibles desde la orilla del río, pero tal como describe VidalSenèze, con bastante dificultad y trepando.

e. Las fotos de Louis Langlois de Piedra Grande del Utcubamba de 1933 muestran claramente sarcófagos del actual Cerro Ángulo.

5. En el sitio Piedra Grande del Utcubamba/Cerro Ángulo se ha podido identificar el grupo de sarcófagos que con alta probabilidad corresponde a aquél visitado y parcialmente destruido por Pierre Vidal-Senèze en 1877 , es decir el sitio preciso de la proveniencia de la momia chachapoya expuesta en París a partir de 1878. Para sustentar esta hipótesis se cuenta con los indicios siguientes:

a. Se trata de un grupo de sarcófagos, no de sarcófagos aislados.

b. Es accesible, pero con dificultad, desde la orilla del río Utcubamba, mientras los otros grupos son de aparente inaccesibilidad.

c. Hay por lo menos cuatro sarcófagos destruidos, lo que corresponde al número de sarcófagos destruidos por Vidal-Senèze.

d. La destrucción no es reciente.

e. El lugar ostenta una pintura rupestre, el Bastón con cuchillo, que es una clara señal de la tumba de un guerrero, como lo fue el individuo momificado en cuestión.

f. No se encontró otros grupos de sarcófagos que cumplan con más de un criterio de los aquí mencionados.

6. Sin embargo la destrucción generalizada del sitio arqueológico Cerro Ángulo deja abierta una posibilidad pequeña de que pueda haber existido otro grupo de sarcófagos que también cumpla con las características indicadas y que pueda haber sido el sitio del cual proviene la momia. Solamente una investigación arqueológica exhaustiva del lugar podrá excluir esta posibilidad por completo.

\section{Agradecimientos}

Quiero agradecer profundamente a Clément Laronde por las fotos de la momia en el Museo del Hombre, donde contó con el apoyo de Anne Raggi, restauradora de las momias de este museo, quien también aportó datos y contactos importantes; a Alejando Alvarado Santillán de la Escuela Nacional Superior Autónoma de Bellas Artes del Perú de Chachapoyas; al Instituto Iberoamericano de Berlín, que dio los permisos para tomar la fotografía de la momia del libro de Hamy; a Michaela Ziemendorff por la revisión del presente artículo; a Úrsula Córdova Benzaquén, Kyle Mosher y Xavier de Thoisy por apoyarme con trabajos de traducción; así como a Napoleón y Manuel Vargas Zubiate, Manuel Vargas Rojas, Alexander Díaz Muñoz, Eudilio Culqui Huamán y Rómulo Silva Vargas.

\section{Bibliografía}

Andersen, W. V. (1967). «Gauguin and a Peruvian Mummy». Burlington Magazine, 109 (769), 238-242.

Anónimo (1882). «Ouverture de l'exposition ethnographique du Trocadéro: l'Amérique». L'Illustration, 15.4.1882 (80), 241.

Bischoff, U. (2005).Edvard Munch (1863-1944). Bilder vom Leben und vom Tod. Colonia: Taschen.

Bou, C.; Benali, L.; Lair, C. y Ansart, A. (2016). Momias Chachapoya y trepanación por perforación: un estudio antropológico experimental. Exposición en el 9no Congreso internacional de estudios sobre momias, Lima.

Fabre, O. (2000). La culture préhispanique Chachapoya, Pérou, mémoire de maîtrise. París: Universidad París IV, Sorbona.

Field, R. S. y Gauguin, P. (1973). Paul Gauguin: Monotypes. Publication on the occasion of the exhibition at the Philadelphia Museum of Art, March 23 to May 13, 1973. Philadelphia: Philadelphia Museum of Art.

Flornoy, B. (1945). Voyages en Haut-Amazone Trois français chez les indiens rédecteurs de têtes Bertrand Flornoy. París: Atlantica.

Наму, Е. T. (1897). Galerie américaine du Musée d' Ethnographie du Trocadéro: choix de pieces archéologiques et ethnographiques. Tomo I. París: Ernest Leroux.

Koschmieder, K. y Gaither, C. (2010). «Tumbas de guerreros chachapoya en abrigos rocosos de la provincia de Luya, Departamento de Amazonas». Arqueología y Sociedad, 22, 9-37.

Koschmieder, K. (2012). Jucusbamba: Investigaciones arqueológicas y motivos Chachapoya en el norte de la 
Provincia de Luya, Departamento Amazonas, Perú. Lima: Ministerio de Agricultura.

LANGLOIS, L. (1939). Utcubamba. Investigaciones arqueológicas en el valle de Utcubamba (departamento de Amazonas, Perú). Lima: Museo nacional.

Lastres, J. B. y Cabieses, F. (1960). La trepanación del cráneo en el Antiguo Perú. Lima: Universidad Nacional Mayor de San Marcos.

LuCAs-Championnière, J. (1912). Les origines de la trépanation décompressive. Trépanation néolithique, trepanation pré-colombienne, trépanation des Kabyles, trépanation traditionnelle. París: G. Steinheil.

Middendorf, E.W. (1895). Peru: Beobachtungen und Studien über das Land und seine Bewohner während eines 25jährigen Aufenthalts. Tomo III, Berlín: Robert Oppenheim (Gustav Schmidt).

Musée Du Quai Branly (2006). Le catalogue de l'iconothèque. URL: http://collections.quaibranly.fr/ pod16/ (Consultado el 8 de mayo 2014). París.

Reichlen, H. y Reichlen, P. (1950). „Recherches archéologiques dans les Andes du Haut Utcubamba«. Journal de la Société des Américanistes. 39, 219-246.

Riviale, P. (2000). Los viajeros franceses en busca del Perú antiguo (1821-1914). Lima: IFEA.
Rosenblum, R. (1978). «Edvard Munch: Some Changing Contexts». En: Edvard Munch: Symbols \& Images. (National Gallery of Art, Ed.), 1-10. Washington D.C.: National Gallery of Art.

Sweetman, D. (1995). Paul Gauguin: A Life. Nueva York: Simon \& Schuster.

Vidal-Senèze, P. y Noetzli, J. (1877). «Sur des momies découvertes dans le Haut Pérou». Bulletin de la Société d'anthropologie de París, 2 (12), 640-641.

Vidal-Senèze, P. (1885). "Voyage dans les républiques de l'Équateur et du Pérou, par MM. Vidal Senèze et Jean Noetzli (1876-1877)». Bulletin de la Société de géographie, 7 (6), 523-593.

ZiemendorfF, S. (2014). «La momia de un sarcófago de la cultura chachapoyas en la obra de Paul Gauguin». Cátedra Villarreal, 2 (2), 107-127.

ZiemendorfF, S. (2015). «Edvard Munch y la momia de un sarcófago de la cultura chachapoyas». Cátedra Villarreal, 3 (2), 197-212.

ZiemendorfF, S. (2016). «La momia chachapoya en el arte después de Paul Gauguin y Edvard Munch». Cátedra Villarreal, 4 (2), 149-167. 